\title{
Autosomal Recessive Cytochrome B- Positive Chronic Granulomatous Disease Type I
}

National Cancer Institute

\section{Source}

National Cancer Institute. Autosomal Recessive Cytochrome B-Positive Chronic

Granulomatous Disease Type I. NCI Thesaurus. Code C154314.

An autosomal recessive form of chronic granulomatous disease caused by mutation(s) in the NCF1 gene, encoding neutrophil cytosol factor 1. 